\title{
Reproductive health at the crossroads
}

\section{Lindsay Edouard}

International Advisory Editor, Port Louis, Mauritius

\section{Correspondence to} Professor Lindsay Edouard; soranae@gmail.com

Received 2 July 2015 Accepted 27 July 2015

\section{CrossMark}

To cite: Edouard L. J Fam Plann Reprod Health Care 2015:41:303-305.

\section{SUMMARY}

Twenty-five years ago, in 1990, family planning (FP) professionals were concerned about the implications of European Community (EC) policies for future directions regarding service delivery. With budgetary threats in the UK, the value of contraceptive services for avoiding abortions and improving maternal health was highlighted. Twenty-five years on, in 2015, sexual and reproductive health (SRH) services are thriving internationally, as reflected in recent activities relating to the Millennium Development Goals (MDGs) and in their position within the Sustainable Development Goals (SDGs) during discussions at the United Nations (UN) on policy for cohesive approaches to international development assistance.

\section{EUROPEAN CONSIDERATIONS}

In 1990, the profession was getting ready for the challenges of "Europe 1992", the EC initiative aimed at creating a single market for the free movement of all services. This included directives for recognition of professional qualifications and harmonisation of standards for essential care. Vast differences existed between the 12 EC countries in the provision and utilisation of FP services and in provision for meeting the needs of certain groups such as the young, people with disabilities and HIV-positive individuals. ${ }^{1}$ Furthermore, there was apprehension regarding the role of the private sector, whether in decreasing access to clinical care or in the lowering of standards by the need to procure cheaper but potentially less effective drugs and other commodities due to the forces of competition.

The Family Planning Association was alarmed at "unjustified cuts and closures across the country" in the provision of clinic services. They sought "vital information in confidence" on such threats from service providers at the grassroots level, with the guarantee that their interventions, with both health authorities and the media, would be carried out "without mentioning the source of the information". 2 Those concerns for the future funding of FP services in the UK led to a written reassurance by the Minister of Health who also specified that "family planning is an important preventive service which contributes to better maternal and child health and to the stability of family life". ${ }^{3}$ In the context of European collaboration, the comparative advantages of both the legal framework and service delivery of FP services in Britain were recognised, and as a result there were great expectations that "contributing to their spread in Europe may aid their retention here". ${ }^{1}$

\section{SYMBOLISM}

With this Journal being the official publication of the National Association of Family Planning Doctors, the editorial team reminded the readership of Greco-Roman mythology as the rationale for its logo. The rod of Aesculapius, the symbol of medicine, with its single entwined serpent, should not be confused with the winged Caduceus rod with its two entwined serpents, the emblem of Mercury, "the god of messengers, of traders - and of thieves!". ${ }^{4}$ Without specifying the mercantile aspects of the provision of health services by the private sector, that article focused on aspects relating to the concept of reproductive health itself. Aesculapius, the son of Apollo, was born by cutting through the uterus of his mother who had either died during labour or been murdered for adultery. Aesculapius had nine children including a son out-of-wedlock and "two bonny girls, Hygeia and Panacea" who were the goddesses of health and cures, respectively. The importance of those four individuals is reflected by the opening part of the traditional 
Hippocratic Oath: "I swear by Apollo the physician and by Aesculapius and Hygeia and Panacea and all the gods and goddesses as my witnesses...”. Finally, another possible link was drawn between FP and the serpent: in the Bible's Book of Proverbs, Solomon considers that "Another of these four wonderful things was 'the way of a man with a maid". 4

\section{CHOICE}

Prevailing mythology on contraception can be defined by the perspectives of religious groups, as exemplified by the situation when "a Quaker group caused quite a furore by acclaiming the Pill for enabling 'maid and man' to enjoy sex on an equal footing for the first time". ${ }^{5}$ With all the rhetoric on gender, it is not often appreciated that technological developments in female-controlled methods of contraception were a crucial step forward in providing practical benefits to women and as a result "the increasing freedom of choice for women and increased control over their own lives that they could now exercise" had constituted the greatest advance in our society at that time.

It might be said that contraception depends largely on a system of deferred gratification, whereby efforts only lead to anticipated accrued rewards later on. ${ }^{6}$ It was therefore not surprising that induced abortion continued to be common despite the added availability of postcoital contraception. As the term "morningafter pill" had led to "misconceptions about the time limit for treatment", emergency contraception was suggested as being a more appropriate term.

The choice of individuals regarding contraception and abortion was fully respected. It was undeniably felt that professionals should avoid "playing the ostrich" and instead should recognise that services for induced abortion would still be needed even when sexually active women had easy access to effective contraception care. ${ }^{8}$ As the "universal distaste for abortion can easily be forgotten" and "essentially, we are all anti-abortionists", the readership was reminded that "no doctor, whatever his personal beliefs, wants to do an abortion" and "the woman with the unwanted pregnancy is the greatest 'anti-abortionist' of us all". ${ }^{8}$ When facing a personal situation involving an unwanted pregnancy, women are known to discard any personal strong objections so as to seek an induced abortion by pleading a special case. Clinical decision-making ideally focuses upon legal, professional and ethical frameworks in seeking solutions to those special circumstances, by avoiding generalisations in order to respect and accommodate the wishes and unmet needs of the pregnant woman. It was noted that some health professionals had visited all women undergoing abortion in hospitals as in "those less cost-conscious days, nothing was felt to be more costly than an unplanned pregnancy". 9

\section{CURRENT IMPLICATIONS}

And now, 25 years on, we can be proud that as proposed in 1990, the recognition of SRH increased its prestige among medical specialties internationally and facilitated recruitment to its training grades, thereby improving service delivery whilst avoiding the medicalisation of problems. ${ }^{10}$ The Faculty of Sexual \& Reproductive Healthcare has been fully committed to international issues and this is also reflected in the widening range of origins of articles in this Journal.

For political reasons, sexual health failed to receive its due prominence in the UN Millennium Declaration of 2000, when emphasis was placed on maternal health. Corrective action was taken 6 years later with the revision of indicators for monitoring progress towards the attainment of the MGDs. Sexual health includes components such as contraception, sexually transmitted infection and sexual orientation which, like abortion, are issues that society likes to avoid: it tends to be neglected to the advantage of maternal and neonatal health, which receives undue consideration for media coverage, resource mobilisation and staff deployment. Abortion is the registered cause of $8 \%$ of maternal deaths worldwide but the figure is likely to be an underestimate in view of failure to disclose the condition due to stigma: in the case of second-trimester abortions, haemorrhage and sepsis are probably registered as causes. With obstetric haemorrhage and peripartum sepsis being major causes of maternal mortality, and in view of the pivotal role that Queen Charlotte's Hospital played in the control of puerperal sepsis, ${ }^{11}$ we could perhaps propose a future role for Queen Charlotte's modern namesake, Princess Charlotte, in the promotion of integrated SRH!

The challenge for international health currently consists of having resilient health systems that can ensure quality of care while stimulating demand for achieving universal coverage of services: the situation worsens when the public demands the latest technology as this can lead to the ineffective use of scarce resources, especially in countries with poor governance. ${ }^{12}$ The lengthy negotiations for setting the post-2015 development agenda, with its global priorities to guide policy formulation during the next 15 years, were difficult because of competing priorities from other sectors. ${ }^{13}$ By consolidating the gains from the MDGs whilst aiming to complete their unfinished business, the list of 17 SDGs incorporates new priorities. Goal 3 seeks to "ensure healthy lives and promote well-being for all at all ages" and its targets include the reduction of maternal mortality and universal access to SRH services, which is also recognised in Goal 5 on gender equality. ${ }^{14}$ While the post-2015 development agenda is being decided at the UN Summit at the end of September 2015, the process of finalising the list of measurable indicators will continue until early $2016 .{ }^{15}$ Designed to serve as proxy measures to monitor progress, indicators can unfortunately be misused through subsequent national policy formulation that focuses 
exclusively on related narrow interventions, to the detriment of effective actions that have more substantial impact on the agreed goals and targets. As some sexual health issues unfortunately remain far too politically controversial for incorporation into any intergovernmental consensus, it is hoped that many countries and donors will be emboldened to go well beyond the agreed targets of the SDGs, to enhance their activities for the promotion of sexual well-being.

Competing interests None declared.

Provenance and peer review Not commissioned; internally peer reviewed.

\section{REFERENCES}

1 Bromham DR. What will we do in 1992? Br J Fam Plann 1990;16:81-83.

2 Kenmir B. NHS family planning clinic closures. Br J Fam Plann 1990;16:79.

3 Bottomley V. Important correspondence. Br J Fam Plann 1990;16:15.

4 Anonymous. NAFPD - the serpent of healing. Br J Fam Plann 1990;16:113.

5 Bromham DR. The independent Pill user. Br J Fam Plann 1990;16:1-2.
6 Kite S. Family planning provision: whose needs are being met? Br J Fam Plann 1990;16:109-113.

7 Burton R, Savage W, Reader F. The 'morning after pill' is the wrong name for it - women's knowledge of postcoital contraception in Tower Hamlets. Br J Fam Plann 1990;15:119-121.

8 Forsythe E, Bromham DR. Promotion of choice. Br J Fam Plann 1990;15:105-106.

9 Anonymous. Obituary - Colleen Corry (1904-1989). Br J Fam Plann 1990;15:125.

10 Wilson S. Consultants in medical gynaecology - a career option for our family planning doctors? Br J Fam Plann 1990;15:121-124.

11 Last P. Queen Charlotte's - the story of a hospital. Br J Fam Plann 1990;15:127.

12 Burgis T. The Looting Machine - Warlords, Tycoons, Smugglers and the Systematic Theft of Africa's Wealth. London, UK: William Collins, 2015.

13 Horton R. Why the sustainable development goals will fail. Lancet 2014;383:2196.

14 United Nations (UN). Transforming Our World: The 2030 Agenda for Sustainable Development. New York, NY: UN, 2015.

15 World Health Organization (WHO). Health in the post-2015 Development Agenda. Document A68/14. 68th World Health Assembly. Geneva, Switzerland: WHO, 2015. 